\title{
Prototype Design of Smart MOM Application to Sickly
}

\section{Toddler Screening}

\author{
Mochammad Choirur Roziqin ${ }^{1, *}$ Ida Nurmawati ${ }^{2}$ Niyalatul Muna ${ }^{3}$ \\ ${ }^{1,2,3}$ Department of Health, Politeknik Negeri Jember, Indonesia \\ *Corresponding author.Email: irul@polije.ac.id
}

\begin{abstract}
One of the efforts to reduce morbidity and mortality in infants and toddlers is to use the MTBS approach. The approach is carried out in an integrated manner that focuses on the overall health of children. To reduce mortality, disease, disability, increase the growth and development of children under the age of five. MTBS is an integrated approach in the management of sick infants and toddlers who come for treatment at outpatient facilities in basic health services. MTBS includes preventive and curative elements carried out by families and communities as well as health facilities. The overall use of the MTBS chart can speed up case findings so that it is appropriate in handling sick toddlers and can reduce under-five mortality. However, the implementation of MTBS at the Public health centre is still not optimal. Health workers do not fully implement the MTBS chart during service. MTBS is still difficult to implement manually. Health workers need a system that can speed up the detection of sick toddlers. This study will create an android and web-based application that can detect sick toddlers, provide action and treatment, as well as community-based consultations. Researchers created the SmartMOM application for screening sick toddlers. The system is designed to help health workers take action as early as possible so that patients get help quickly. The research will carry out the process of designing a prototype design for the Android and web-based SmartMOM application. The application is adapted to the MTBS chart and user needs.
\end{abstract}

Keywords: Android, MTBS, Public health centre, prototype, SmartMom.

\section{INTRODUCTION}

Under-five mortality is an important indicator to assess the health status and quality of life of a country. Based on the results of the 2017 IDHS, it is known that the Toddler Mortality Rate is 32 deaths per $1000 \mathrm{KH}$. This figure is higher than the SDGs target of 25 deaths per $1000 \mathrm{KH}$ [1]. One of the efforts to reduce morbidity and mortality in infants and toddlers is to use the Integrated Management of Childhood Illness (MTBS) approach. MTBS is an integrated approach that focuses on the overall health of children to reduce death, disease, disability, and improve the growth and development of children under the age of five. MTBS includes preventive and curative elements carried out by families and communities as well as health facilities [2].

Currently, MTBS has not been implemented optimally. Research on the obstacles to using MTBS has been carried out previously by researchers with DRPM funding in the PDP scheme [3]. Health workers hope that the MTBS chart can be made into a smartphone application that can immediately detect sick toddlers so that health services can be carried out quickly. The results of the study also obtained an android-based application design [4]. The MTBS application that was made is expected to also be used by health cadres to assist health workers in finding cases at the Posyandu. Cadres are an extension of health workers' hands so detecting sick toddlers by involving health cadres is the right step because health cadres are people who are in the toddler's environment who directly know the condition of toddlers. This step can help speed up the discovery of sick toddlers so that sick toddlers get help early [5].

As an effort to follow up on the results of previous studies, the researchers made a prototype design of the 
SmartMOM application for screening sick toddlers. The system is accessible to health workers and the public. This study aims to create an android and web-based application prototype that can detect sick toddlers, provide action, treatment, and community-based consultations.

This research supports government policies in terms of community empowerment for the discovery of sick toddlers. The literature is stated in the Regulation of the Minister of Health number 70 of 2013 concerning the implementation of community-based MTBS. The basic principle of MTBS-M is to establish partnerships between first-level health care facilities and the communities they serve. The android-based application that will be made will be able to establish communication between the community and the public health centre and Hospitals. It is hoped that the MTBS application created can also be used by health cadres to assist health workers in finding cases at the Posyandu. Cadres are an extension of health workers' hands so detecting sick toddlers by involving health cadres is the right step because health cadres are people who are in the toddler's environment who directly know the condition of toddlers [5]. This step can help speed up the discovery of sick toddlers so that sick toddlers get help early [6].

The research has been carried out in three stages. The first is the definition of needs. Second System and software design. Third implementation and unit testing.

\section{RESEARCH METHOD}

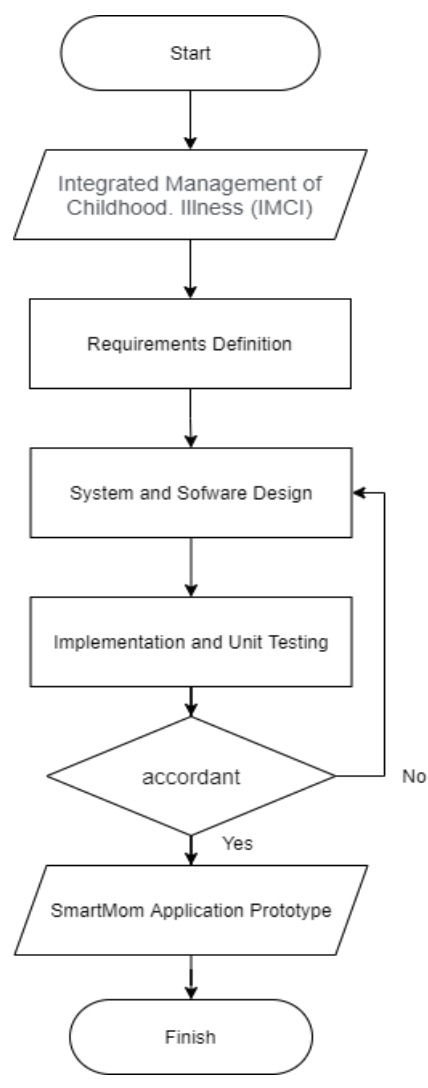

Figure 1 Flowchart Prototype Design of Smart MOM Application

In general, the research flow can be seen in Figure 1. The software system development method used is the waterfall model. The inputs to this research are the Integrated Management of Childhood Illness (MTBS). Flow is done to find out the structure built. The process is listening to user and expert opinions. At this stage, identification of needs is carried out by analyzing what needs will be applied to the application to be designed. After that, the next step is making the application design. The output of this research is SmartMOM Application Prototype.

The results are then tested and implemented in the program to run the prototype view. So that it can be evaluated to users and experts on the menu display and user friendly on the display if there are still things that are not appropriate.

\section{RESULTS AND DISCUSSION}

The results of the design requirements of the system are created in the form of functions [7]. The function that is executed has two main actors. The first acts as a system user can perform the following processes:

1. Access the user's Main Display (Home user), and see a summary of all activities that have been done 
2. Accessing online MTBS, namely Inputting personal data from toddlers to be examined, filling out all the required questionnaires, after that the user will be directed to recommendations for handling based on the results analysis of the questions that have been given

\section{Access articles and news about MTBS}

The second main actor is the admin who manages the SmartMOM application. admin access can log in to a website-based system. The functions that can be accessed by the admin are:

1. Manage master data consisting of symptoms, symptom info, FAQ, disease, and place.

2. Manage users by being able to add, edit, and delete data.

3. Manage dashboard from app main page.

4. Manage patient records and data (Insert, Select, Update, copy, and delete)

Each user must do the login process first in order to access the application. For users who have not registered can do the registration process. The use case

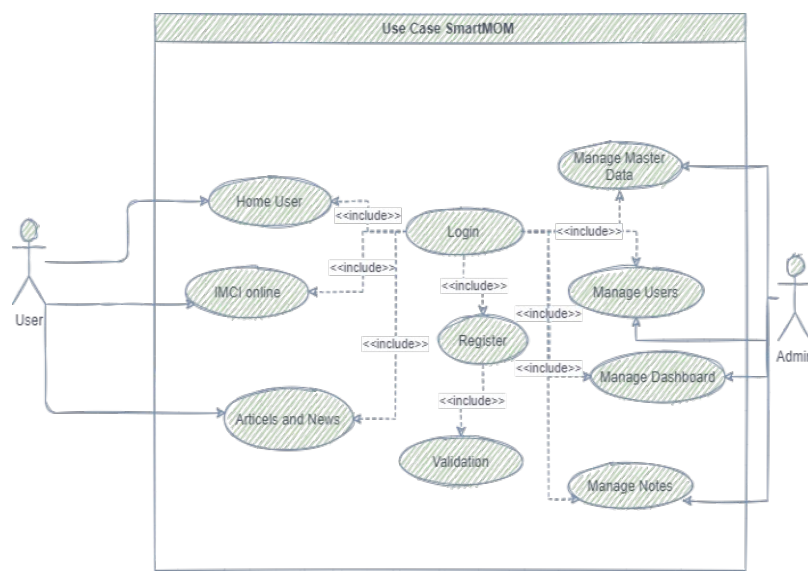

diagram for actors in the SmartMOM application can be seen in figure 2. Once the requirements for the system have been completed are analyzed and identified. Systems and software are designed. Then implemented into a programming language and tested each menu unit for the design results. The stage is only testing the menu display, not yet reaching the programming function.

\section{Figure 2 Use Case of Smart MOM Application}

The results of the design and implementation can be seen in Figures three to seven.

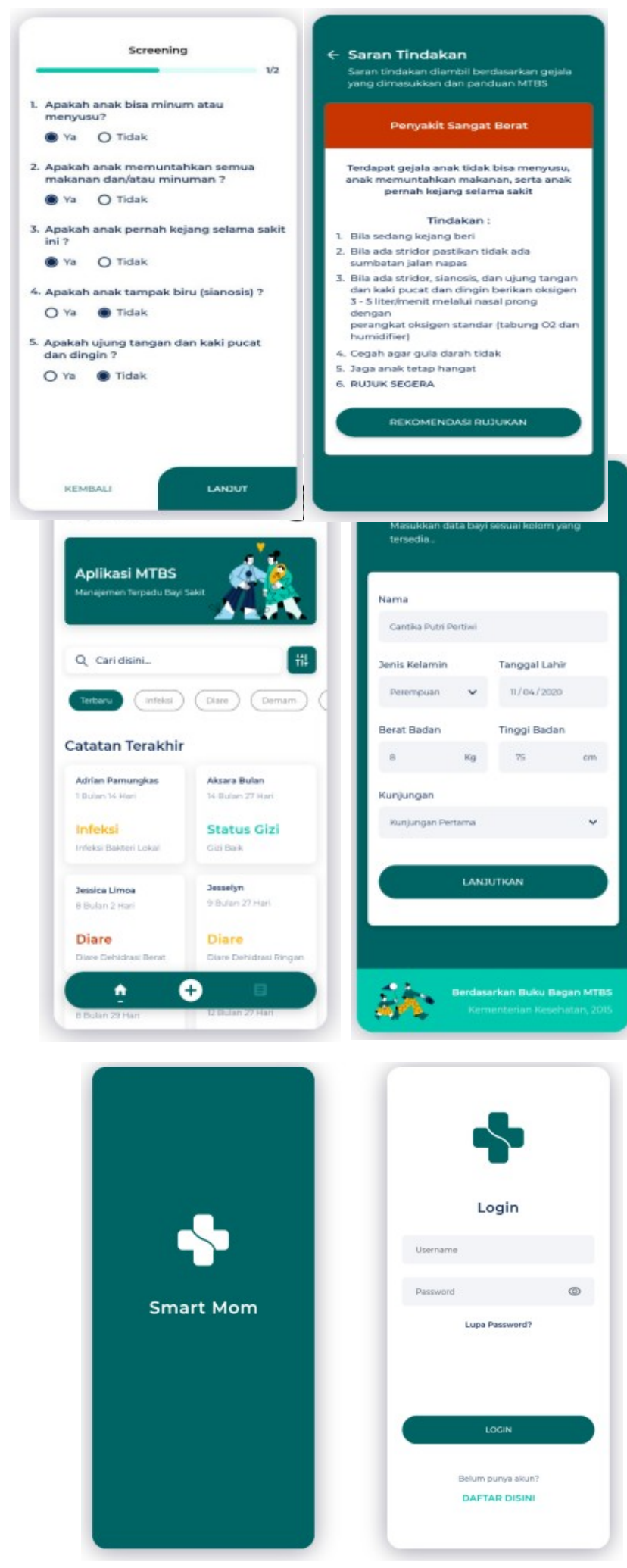

Figure 3 Login Interface of Smart MOM Application 
The initial appearance of the application when first opened is a splash screen that contains information about the name and logo of the application. The interface will appear first after the application is opened. The user must enter a registered account (figure 3). Users can log in using the username and password that has been provided registered.

On the home menu, the user can see a summary of all the activities that have been done. At the menu bar, there is a profile photo, application logo, and user name. There is also a banner on the home section that can be used as a shortcut for articles, announcements, etc. Users can search for existing MTBS data by using the search box provided or by setting it.

Figure 4 Home and MTBS online Interfaces of Smart MOM Application

In this menu MTBS online of entry data menu, the user must first enter the personal data of the toddler to be examined in the form of name, gender, date of birth, weight, height, and gender visit. After complete, the user can press the continue button, then the user Several questions or questionnaires will be given to determine the condition of the toddler examined based on the 2015 Ministry of Health MTBS Chart Book.

Figure 5 Screening and Action Suggestions Interfaces of Smart MOM Application

After filling out all the required questionnaires and then pressing the button further, the user will be directed to treatment recommendations based on the results
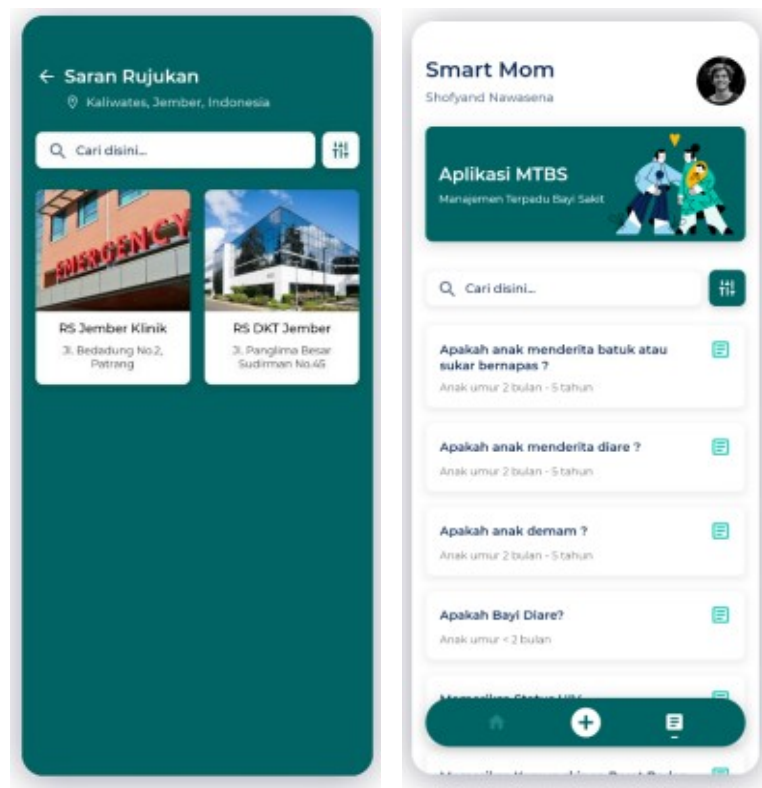

analysis of the questions that have been given. The results of the examination will appear as shown in the image above. Illness will be categorized and given action recommendations as in the MTBS Chart Book. At this stage the user is also given a referral recommendation, the user can press the button Referral Recommendations to see suitable referral recommendations.

Figure 6 Referral suggestions, Article and News Interfaces of Smart MOM Application

The recommendations shown are hospital recommendations with a distance of closest to the user's location. Users can also still search for homes another pain by using the existing search box. This interface contains articles and news about MTBS. User can read how to manage toddler disease manually for each disease here.

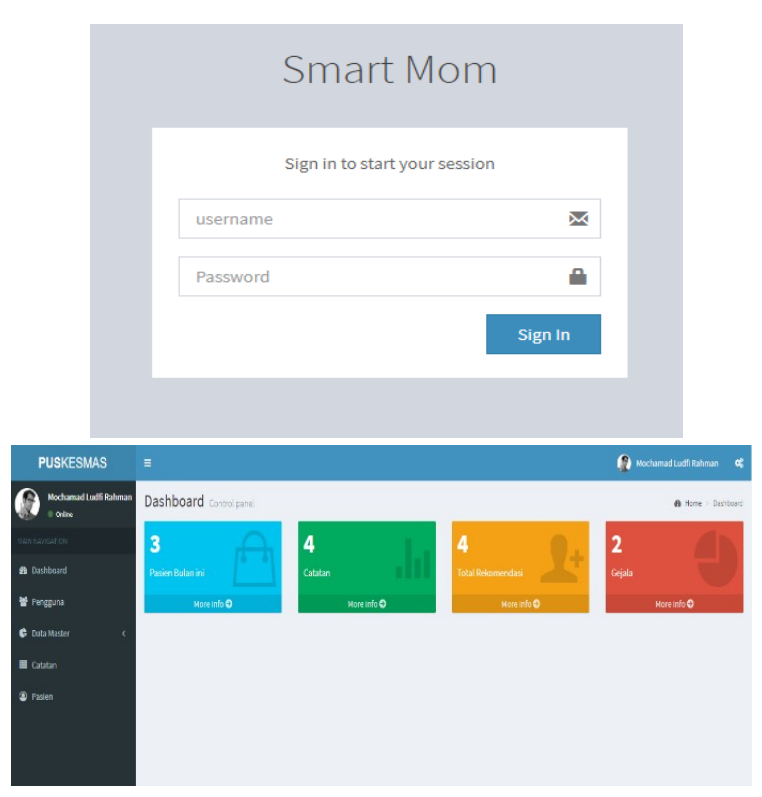

Figure 7 Admin Management Interfaces of Smart MOM Application

The admin management display is used by puskesmas officers in managing the application so that it is appropriate. The functions in the admin page are made web-based. making it easier for users to manage anywhere and can be directly synchronized between data with android-based applications.

\section{CONCLUSION}

The results of the SmartMOM application design have system requirements that have been adjusted to the user. The use case shows that there are two actors needed by the system in the application, namely the user and the admin. For users consisting of health cadres or midwives on duty at posyandu. While the admin is an officer from the Puskesmas. The SmartMOM application design is still a prototype design. The test was carried out with user samples from health cadres, 
midwives, and puskesmas officers. Meanwhile, expert testing was carried out with doctors on duty at the puskesmas.

The display results show conformity to the MTBS chart and can be translated online to make it easier for users. In the future, the system can be implemented as a whole so that the display can run according to the interface and program functions. The intelligence system in the application is also applied to provide actionable suggestions and referral suggestions.

\section{AUTHORS' CONTRIBUTIONS}

The author contributes to supporting government policies in terms of community empowerment for the discovery of sick toddlers. The results of the study can be used as an initial plan for screening sick toddlers and can conduct consultation/communication directly with the health centre staff closest to the toddler's residence. The use of the MTBS chart as a whole can speed up case finding in handling sick toddlers appropriately. This can help reduce infant mortality.

\section{ACKNOWLEDGMENTS}

The author would like to thank the Ministry of Education and Culture of The Republic of Indonesia for the PNBP research funding program with the number: $381 / \mathrm{PL} 17.4 / \mathrm{PG} / 2021$ that has supported this research.

\section{REFERENCES}

[1] Bappenas. SDGs: Kehidupan Sehat dan Sejahtera. Kementerian PPN. http://sdgs.bappenas.go.id/tujuan-3/. Published 2020.

[2] WHO. Integrated Management of Childhood Illness (IMCI). World Health Organization. https://www.who.int/maternal_child_adolescent/to pics/child/imci/en/. Published 2020.

[3] Nurmawati I, Erawantini F. Kebutuhan Perancangan Sistem Screening Balita Sakit Berdasarkan Klasifikasi dan Penatalasanaan MTBS. J Kesehat. 2019;6(3):83-87. doi:10.25047/j-kes.v6i3.18.

[4] Nurmawati I. Android-Based Integrated Management Of Chilhood Illness (Imci) Application Design. J Penelit Kesehatan Suara Forikes. 2020;11(4). https://forikes-ejournal.com/index.php/SF/article/vi ew/838.

[5] Rambaud-Althaus C, Shao AF, Kahama-Maro J, Genton B, D'acremont V. Managing the sick child in the era of declining malaria transmission:
Development of ALMANACH, an electronic algorithm for appropriate use of antimicrobials. PLoS One. 2015;10(7):1-19. doi:10.1371/journal.pone.0127674.

[6] Titaley C, Jusril H, Ariawan I, Soeharno N, Setiawan T, Weber M. Challenges to The Implementation of The Integrated Management of Childhood Illness (IMCI) at Community Health Centres in West Java Province, Indonesia. WHO South-East Asia J Publich Heal. 2014;3(2):161170.

[7] Niyalatul Muna, Ervina Rachmawati, Ida Nurmawati. Design of Nutritional Status System for Stunting Early Prevention. Advances in Social Science, Education and Humanities Research, volume 514. 2020;514:140-144 Proceedings of the First International Conference on Social Science, Humanity, and Public Health (ICOSHIP 2020). Atlantis Press. doi: https://doi.org/10.2991/assehr.k.210101.031. 